\title{
Review
}

\section{Functional Connectivity Signatures of Parkinson's Disease}

\author{
Alessandro Tessitore ${ }^{\mathrm{a}, \mathrm{b}, *}$, Mario Cirillo ${ }^{\mathrm{a}, \mathrm{b}}$ and Rosa De Micco ${ }^{\mathrm{a}, \mathrm{b}}$ \\ a Department of Advanced Medical and Surgical Sciences, University of Campania "Luigi Vanvitelli", \\ Naples, Italy \\ b MRI Research Center SUN-FISM, University of Campania "Luigi Vanvitelli", Naples, Italy
}

Accepted 20 July 2019

\begin{abstract}
Resting-state functional magnetic resonance imaging (RS-fMRI) studies have been extensively applied to analyze the pathophysiology of neurodegenerative disorders such as Parkinson's disease (PD). In the present narrative review, we attempt to summarize the most recent RS-fMRI findings highlighting the role of brain networks re-organization and adaptation in the course of PD. We also discuss limitations and potential definition of early functional connectivity signatures to track and predict future PD progression. Understanding the neural correlates and potential predisposing factors of clinical progression and complication will be crucial to guide novel clinical trials and to foster preventive strategies.
\end{abstract}

Keywords: Functional MRI, imaging, biomarkers, Parkinson's disease, resting-state networks

\section{INTRODUCTION}

Parkinson's disease (PD) is a chronic neurodegenerative disorder with a point prevalence ranging from $0.25-4 \%$ between age of $65-80$ [1]. Degeneration of nigrostriatal dopaminergic neurons resulting in disruption of basal ganglia-thalamo-cortical loops, underlies the classical motor signs and symptoms of PD. The typical motor PD signs may be preceded by a period that lasts several years to decades, in which the neurodegeneration process is already started and spreads throughout the nervous system [2]. This early phase is characterized by a broad range of slight motor and/or non-motor features (i.e., hyposmia, sleep disturbances, mood disorders, pain, etc.), or might even have no clinical expression. In this phase a clinical diagnosis of PD as for current

\footnotetext{
*Correspondence to: Alessandro Tessitore, MD, PhD, Department of Advanced Medical and Surgical Sciences, University of Campania "Luigi Vanvitelli", 80138 Naples, Italy. E-mail: alessandro.tessitore@unicampania.it.
}

diagnostic criteria [3] is not allowed. However, this prodromal stage is gaining more attention as neuroprotective treatment in early stages could prevent clinical PD from emerging, revolutionizing the history of disease [2].

After a clinical diagnosis has been made, dopamine replacement therapy (DRT) is the most effective treatment for patients with PD [4]. However, DRT is complicated by the evolution of motor complications, including motor response fluctuations and levodopainduced dyskinesias (LID) [5], which may develop progressively, with up to $80 \%$ of levodopa-treated patients showing involuntary movements after 4-6 years of treatment, and up to $90 \%$ after 10 years $[6$, 7]. Risk factors for developing LID include long treatment duration, high initial dose of levodopa, young age at onset, low body weight, female sex, but yet these factors alone cannot predict whether an individual patient will develop LID [6].

As the disease progresses, cognitive function in PD deteriorates over time [8], severely influencing the motor outcome as well as the patients' quality of 
life and prognosis $[8,9]$. The spectrum of cognitive symptoms in PD is heterogeneous, ranging from mild cognitive impairment (MCI) to dementia (PDD) [9]. In one long-term study, dementia was present in $83 \%$ of those patients surviving for $>20$ years [10].

Currently, premotor diagnosis as well as prediction of PD complications is one of the main goal of the current PD research. In this framework, neuroimaging techniques such as functional MRI (fMRI) have recently provided several insights into the pathophysiology of PD and some suggestions about treatment and progression-related changes.

Functional connectivity is defined as the temporal coherence of neuronal activity patterns emerging from anatomically separated brain regions [11], and therefore is thought to rely and express the functional communication between them. The blood oxygen level dependent (BOLD) signal provides a link between the neuronal activity, arising during information processing, and the MRI signal strength. As it has been demonstrated that the BOLD signal reflects the firing of neural populations with a strong correlation between its amplitude and local field potentials data [12], it has been suggested that BOLD signal is more related to synaptic activity rather than neural activity per se, providing information about the processing of neuronal information at the synaptic level.

During the last decade, researchers have assessed the spontaneous oscillations of the BOLD signal at rest in both healthy and pathological brain [13, 14], revealing the presence of consistent intrinsic' resting-state (RS) spatially distributed functional connectivity networks, called RS networks (RSNs). Compared to task-based fMRI, RS-fMRI allows to study simultaneously different networks, improving the chances to detect disease-related connectivity disturbances.

The spontaneous fluctuations of RS BOLD signals are generally low frequency oscillations, observed between 0.01 and $0.08 \mathrm{~Hz}$ frequency band [13]. Recent studies have shown that these low frequency temporal components reflect spontaneous fluctuations of brain physiology and metabolism $[15,16]$.

Several analytic approaches have been applied to study the RSNs $[17,18]$. Seed-based approach is a common method to investigate the functional connectivity between a preselected seed or region of interest (ROI) and other brain voxels. Thus, seed-based studies provide information about the functional coupling between the averaged BOLD time course of a predetermined seed and the BOLD time courses of other voxels across the whole brain. This method requires an a priori hypothesis, and a rigorous selection of appropriate ROIs. Independent component analysis (ICA) is the most common data-driven method to isolate functional connectivity networks from fMRI data and does not necessarily need a previous assumption. This method can be applied to assess the spatial distribution of the coherence of BOLD signals across all brain voxels [19], within the most reported and investigated RSNs (Fig. 1):

- Default-mode network (DMN): it is involved in introspection, mind-wandering, active episodic memory and becomes deactivated during specific goal-directed behavior. It encompasses mainly precuneus and posterior cingulate, bilateral inferior-lateral-parietal and ventromedial frontal cortices.

- Sensorimotor network (SMN): it has a central role in detection and processing of sensory input and preparation and execution of motor functions. It comprises the primary sensorimotor cortex, supplementary motor area (SMA) and secondary somatosensory cortices.

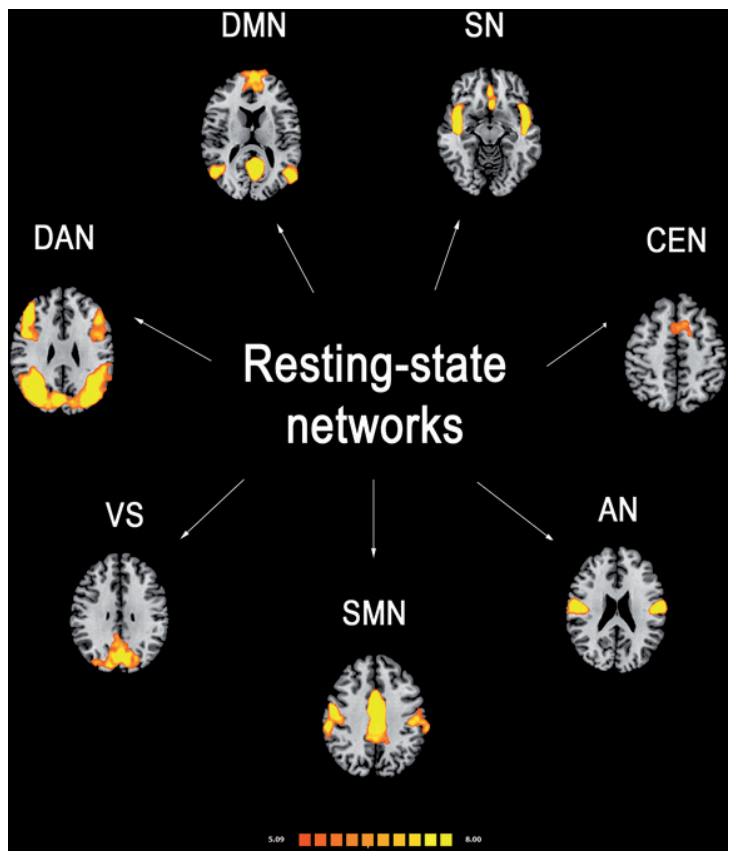

Fig. 1. Most reported resting-state functional connectivity networks in healthy controls. Mean resting-state functional MRI imaging networks shown in axial view and three-dimensional reconstructions $(p<0.05$ corrected). Colors represent percentage BOLD signal change, overlaid on the average anatomic images in standard space. DMN, default-mode network; SN, salience network; CEN, central executive network; DAN, dorsal attention network; SMN, sensorimotor network; VS, visual network; AN, auditory network. 
- Central executive networks (CEN): it is involved in executive control and working memory function and operates across mesiofrontal areas, including anterior cingulate and para-cingulate cortices.

- Salience network (SN): it detects and responds to behaviorally salient events and encompasses manly the dorsal anterior cingulate cortex and bilateral insulae.

- Dorsal attention (DAN): it is involved in voluntary (top-down) orienting and selective attention. Superior parietal and superior frontal areas, including intraparietal sulcus and frontal eyefields are the most involved cortical areas;

- Auditory network: it is involved the right and left primary auditory cortex, Heschl's gyrus, lateral superior temporal gyrus and posterior insular cortex.

- Visual network: cortical areas involved in this network and function are mainly the lateral and superior occipital gyrus as well as the lingual gyrus.

Several studies have shown the presence of a functional reorganization within these networks in PD patients [20], but how each network interacts to the others has been also investigated. Indeed, specific functional coupling/decoupling patterns have been shown between the RSNs [21, 22], and this seems to be crucial for the so-called neurocognitive networks (i.e., DMN, CEN, SN, DAN), which are critical to generate and maintain an efficient behavioral and cognitive performance [22, 23].

Another analytic method for RS-fMRI data is the graph theoretical analysis. With this approach, anatomic brain regions are considered to be nodes, linked by edges, which represent the connectivity measured by the temporal correlation of BOLD fluctuations between the nodes. To date, only a few RS-fMRI studies using graph theoretical approach have been conducted in patients with PD [24-31] with a degree of inconsistency between studies mostly related to the small number of subjects or the inclusion of subjects across different PD stages.

It is important to note that at this stage caution needs to be taken in the context of translation RSfMRI into clinical practice. Indeed, to date there is a lack of standardization of RS-fMRI acquisition and analysis methods and concerns about its reliability have been raised [32, 33]. In PD patients, reproducibility of functional connectivity alterations has been the focus of a recent study by Badea and colleagues [32] where three independent RS-fMRI datasets have been analysed with the same workflow. Only a few brain regions showed marginally consistent functional connectivity changes across all three datasets, with a very low impact from technical issues [32]. However, as the three PD samples were clinically heterogeneous in terms of disease duration and medication status, this may highlight the sensitivity of RS-fMRI in detecting specific neural changes which characterize each disease stage and the effect of dopaminergic treatment on both connectivity and BOLD signal variability.

Some studies also suggest the presence of specific RS-fMRI features at individual level which may also differ from what revealed by group comparisons, with a high rate of reliability across independent datasets [34]. However, RS-fMRI is still not able to provide a comprehensive disease picture at the individual patient level nor to offer ratable measures to compare one single subject to another or to a group of controls.

Nevertheless, other reports have shown high within-subject longitudinal reproducibility of RSNs, suggesting that they might potentially serve as biomarkers for monitoring disease progression [35].

In summary, RS-fMRI is a widely available, noninvasive and cost-effective tool which needs technical and methodological improvements to confirm its potential to support the clinical diagnosis and track PD progression biomarkers.

In this review, we attempt to summarize the most relevant studies supporting the role of RS-fMRI imaging as a potential biomarker of PD pathology and disease progression. We also discuss the prospects for incorporating these biomarkers into future clinical trials to track treatment response and predict complications.

\section{SEARCH STRATEGY}

Articles published on PubMed until December 2018 were checked for the purpose of this review. "Parkinson's disease" were cross-referenced with "resting state functional magnetic resonance imaging". Two independent observers (RDM and AT) evaluated the results, excluding duplicates and articles judged irrelevant by title and abstract screening. The same raters performed the quality check of selected studies and the most relevant ones for the topic were finally included in this narrative review (Table 1). 
Table 1

Summary of the methods and results from the studies included in the review

\begin{tabular}{lll}
\hline Reference & Imaging methods & \multicolumn{1}{c}{ Subjects } \\
\hline Sang et al., 2015 [24] & \multicolumn{1}{c}{ Diagnosis of PD and motor symptoms correla } \\
& Graph-analysis & 26 early PD patients \\
& & vs $30 \mathrm{HC}$
\end{tabular}

Main findings

Decreased global efficiency in PD compared to HC. Increased nodal centrality in bilateral pallidum, inferior parietal lobule, and medial superior frontal gyrus, and decreased nodal centrality in caudate nucleus, supplementary motor areas, precentral gyrus, and middle frontal gyrus in PD compared to HC

Berman et al., 2016 [25] Graph-analysis

19 PD patients vs 16 $\mathrm{HC}$

Increased local efficiency in CEN and SN. Levodopa significantly decreased local efficiency in PD in all networks except within the putamen and caudate

Fang et al., 2017 [27] $\quad$ Graph-analysis 26 early PD vs 19 HC

Decreased nodal degree, global efficiency, local efficiency and characteristic path length within the SMN and VN in PD compared to HC. Higher nodal degree, global efficiency and local efficiency, and lower characteristic path length within DMN and cerebellum in PD compared to HC. Lower cluster coefficient in thalamus and caudate nucleus in PD compared to $\mathrm{HC}$

Suo et al., 2017 [28] Graph-analysis 153 PD vs 81 HC

Decreased clustering coefficient, global efficiency, and local efficiency, and increased characteristic path length as well as decreased nodal centralities in the SMN, $\mathrm{DMN}$, and temporal-occipital regions in PD compared to $\mathrm{HC}$

\begin{tabular}{|c|c|c|}
\hline $\begin{array}{l}\text { de Schipper et al., } 2018 \\
\text { [30] }\end{array}$ & Graph-analysis & $107 \mathrm{PD}$ vs $58 \mathrm{HC}$ \\
\hline Hou et al., 2018 31] & Graph-analysis & $\begin{array}{l}20 \text { early akynetic PD } \\
\text { vs } 20 \mathrm{HC}\end{array}$ \\
\hline
\end{tabular}

Increased eigenvector centrality within frontoparietal regions in PD compared to HC. Increased connectivity in the SMN and VN in PD compared to HC.

Lower nodal centralities in the occipital lobe and areas of the limbic system and higher nodal centralities in frontal and temporal regions in $\mathrm{PD}$ compared to $\mathrm{HC}$

Tuovinen et al., 2018 [51] Graph-analysis 16 early PD vs 16 HC

At baseline, increased connectivity between cerebellum and SMN as well as decreased connectivity between motor regions and cingulate cortex in PD compared to HC. At 1.5 years follow-up, increased cerebellum connectivity within itself and to the caudate nucleus, thalamus and amygdala in PD compared to HC

\begin{tabular}{|c|c|c|c|}
\hline Wu et al., 2009 [42] & $\begin{array}{l}\text { Seed-based analysis (M1, } \\
\text { bilateral cerebellum, SMA, } \\
\text { cingulate motor area, globus } \\
\text { pallidus, putamen, thalamus, } \\
\text { parietal cortex, and DLPFC) }\end{array}$ & $22 \mathrm{PD}$ vs $22 \mathrm{HC}$ & $\begin{array}{l}\text { Decreased functional connectivity in the } \\
\text { SMA, left DLPFC and left putamen as well } \\
\text { as increased functional connectivity in the } \\
\text { left cerebellum, left M1, and left parietal } \\
\text { cortex in PD compared to HC. Levodopa } \\
\text { relatively normalized functional connectivity } \\
\text { in PD }\end{array}$ \\
\hline Wu et al., 2011 [43] & $\begin{array}{l}\text { Seed-based analysis } \\
\text { (pre-SMA and M1) }\end{array}$ & $18 \mathrm{PD}$ vs $18 \mathrm{HC}$ & $\begin{array}{l}\text { Increased connectivity between pre-SMA } \\
\text { and M1 as well as decreased connectivity } \\
\text { between pre-SMA and putamen, right insula, } \\
\text { right premotor cortex, and left inferior } \\
\text { parietal lobule in PD patients compared to } \\
\text { HC }\end{array}$ \\
\hline
\end{tabular}


Table 1

(continued)

\begin{tabular}{lll}
\hline $\begin{array}{l}\text { Baudrexel et al., 2011 } \\
\text { [46] }\end{array}$ & Seed-based analysis (STN) & 31 early PD vs 44 HC \\
\hline Hacker et al., 2012 [50] & $\begin{array}{l}\text { Seed-based analysis (anterior } \\
\text { and posterior putamen, } \\
\text { caudate) }\end{array}$ & $\begin{array}{l}13 \text { advanced PD vs 19 } \\
\text { HC }\end{array}$ \\
\hline
\end{tabular}

Increased connectivity between STN and cortical motor areas in PD compared to HC

Decreased striatal connectivity with

thalamus, midbrain, pons and cerebellum in

PD compared to HC. Decreased functional connectivity in sensori-motor and visual areas as well the supramarginal gyrus in PD compared to HC

\begin{tabular}{lll}
\hline Agosta et al., 2014 [45] & Seed-based analysis (caudate & $\begin{array}{l}\text { 69 PD (25 early PD) } \\
\text { vs 27 HC }\end{array}$
\end{tabular}

Decreased connectivity within striatal and and putamen nuclei, globus vs $27 \mathrm{HC}$ thalamic regions as well as increased pallidus, and thalamus) connectivity between striatum and temporal cortex, and between thalamus and several sensorimotor, parietal, temporal, and occipital regions in PD patients compared to early PD and HC

\begin{tabular}{ll}
\hline Manza et al., 2016 [49] & $\begin{array}{l}\text { Seed-based analysis } \\
\text { (putamen, caudate and their } \\
\text { subregions) }\end{array}$
\end{tabular}

Higher motor impairment at baseline and over 1 year was correlated with decreased coupling between anterior putamen and midbrain. Higher decline in cognitive function was associated with increased coupling between the dorsal caudate and the rostral anterior cingulate cortex

\begin{tabular}{|c|c|c|c|}
\hline $\begin{array}{l}\text { Jech et al., } 2013 \text { [53] } \\
\text { Mueller et al., } 2018 \text { [54] }\end{array}$ & Eigenvector centrality & 24 PD patients & $\begin{array}{l}\text { Increased functional connectivity between } \\
\text { cerebellum and thalamus, putamen, globus } \\
\text { pallidus, and brainstem in PD after levodopa } \\
\text { intake compared to OFF state }\end{array}$ \\
\hline Esposito et al., 2013 [44] & $\begin{array}{l}\text { ICA-based and fALFF } \\
\text { analyses (SMN) }\end{array}$ & 20 early PD vs $18 \mathrm{HC}$ & $\begin{array}{l}\text { Decreased connectivity within the SMA in } \\
\text { PD compared to HC. Levodopa increases } \\
\text { SMN connectivity }\end{array}$ \\
\hline Rolinski et al., 2015 [38] & ICA-based analysis (BGN) & $\begin{array}{l}32 \text { early PD vs } 19 \mathrm{HC} \\
\text { vs } 31 \mathrm{AD}\end{array}$ & $\begin{array}{l}\text { Decreased connectivity within the BGN in } \\
\mathrm{PD} \text { compared to } \mathrm{AD} \text { and } \mathrm{HC} \text { with the } \\
\text { greatest change seen in the posterior putamen }\end{array}$ \\
\hline Tessitore et al., 2012 [61] & $\begin{array}{l}\text { ICA-based analysis (DMN, } \\
\text { FPN, SN) }\end{array}$ & $\begin{array}{l}29 \text { PD (16 with vs } 13 \\
\text { without FOG) vs } 15 \\
\text { HC }\end{array}$ & $\begin{array}{l}\text { Decreased functional connectivity in the } \\
\text { right occipito-temporal gyrus within FPN } \\
\text { and VS in PD with FOG compared to those } \\
\text { without }\end{array}$ \\
\hline Fling et al., 2014 [62] & $\begin{array}{l}\text { Seed-based analysis (SMA, } \\
\text { STN, mesencephalic and } \\
\text { cerebellar locomotor regions) }\end{array}$ & $\begin{array}{l}15 \text { PD ( } 8 \text { with vs } 7 \\
\text { without FOG) vs } 14 \\
\text { HC }\end{array}$ & $\begin{array}{l}\text { Increased functional connectivity between } \\
\text { the SMA and mesencephalic as well as } \\
\text { cerebellar motor regions in PD with FOG } \\
\text { compared to those without and HC }\end{array}$ \\
\hline Canu et al., 2015 [63] & $\begin{array}{l}\text { ICA-based analysis (SMN, } \\
\text { DM, VN, SN, and right FPN) }\end{array}$ & $\begin{array}{l}53 \text { PD ( } 28 \text { with vs } 25 \\
\text { without FOG) vs } 35 \\
\text { HC }\end{array}$ & $\begin{array}{l}\text { Decreased functional connectivity in the M1 } \\
\text { and SMA within the SMN as well as in } \\
\text { frontoparietal regions within the DMN, and } \\
\text { occipital cortex within the VS in PD with } \\
\text { FOG compared to HC }\end{array}$ \\
\hline Chen et al., 2015 [57] & ALFF analysis & $\begin{array}{l}31 \text { PD (12 TD vs } 19 \\
\text { PIGD) vs } 22 \text { HC }\end{array}$ & $\begin{array}{l}\text { Increased connectivity in the right cerebellar } \\
\text { posterior lobe in TD compared to HC as well } \\
\text { as decreased connectivity in the putamen and } \\
\text { cerebellar posterior in PIGD compared to } \\
\text { HC. Increased connectivity in the bilateral } \\
\text { putamen and the cerebellar posterior lobe, as } \\
\text { well as decreased connectivity in the } \\
\text { bilateral temporal gyrus and the left superior } \\
\text { parietal lobule in TD compared to PIGD }\end{array}$ \\
\hline $\begin{array}{l}\text { Karunanayaka et al., } 2016 \\
\text { [58] }\end{array}$ & $\begin{array}{l}\text { ICA-based analysis (DMN); } \\
\text { ALFF analysis }\end{array}$ & $\begin{array}{l}17 \text { akynetic PD vs } 15 \\
\text { TD vs } 24 \mathrm{HC}\end{array}$ & $\begin{array}{l}\text { Decreased connectivity in the left inferior } \\
\text { parietal cortex and the left posterior } \\
\text { cingulate cortex within the DMN in akynetic } \\
\text { PD compared to HC and TD }\end{array}$ \\
\hline
\end{tabular}


Table 1

(continued)

\begin{tabular}{|c|c|c|}
\hline Ma et al., 2017 [29] & Graph-analysis & $\begin{array}{l}31 \text { PD (12 TD vs } 19 \\
\text { PIGD) vs } 22 \text { HC }\end{array}$ \\
\hline
\end{tabular}

Decreased connectivity in the basal ganglia, cerebellum, superior temporal gyrus, preand postcentral gyri, inferior frontal gyrus, middle temporal gyrus, lingual gyrus, insula, and parahippocampal gyrus in PD compared to HC. PIGD had more disrupted hubs in the cerebellum than the TD.

\begin{tabular}{|c|c|c|c|}
\hline \multicolumn{4}{|c|}{ Premotor phase and non-motor symptoms correlates } \\
\hline Rolinski et al., 2016 [40] & ICA-based analysis (BGN) & $\begin{array}{l}26 \mathrm{iRBD} \text { vs } 48 \mathrm{PD} \text { vs } \\
23 \mathrm{HC}\end{array}$ & $\begin{array}{l}\text { BGN connectivity of differentiated iRBD } \\
\text { and PD from HC. No difference between } \\
\text { iRBD and PD }\end{array}$ \\
\hline $\begin{array}{l}\text { Olde Dubbelink et al., } \\
2014 \text { [98] }\end{array}$ & $\begin{array}{l}\text { Seed-based analysis ( } 92 \mathrm{ROI} \\
\text { covering the entire brain) }\end{array}$ & $55 \mathrm{PD}$ vs $15 \mathrm{HC}$ & $\begin{array}{l}\text { Progressive connectivity deterioration in } \\
\text { precentral gyrus, postcentral gyrus, superior, } \\
\text { middle, and inferior occipital gyrus, } \\
\text { calcarine cortex, cuneus, and superior } \\
\text { temporal gyrus over } 3 \text { years in PD patients }\end{array}$ \\
\hline Tessitore et al., 2012 [97] & ICA-based analysis (DMN) & $16 \mathrm{PD}$ vs $16 \mathrm{HC}$ & $\begin{array}{l}\text { Decreased connectivity in the right medial } \\
\text { temporal lobe and bilateral inferior parietal } \\
\text { cortex within the DMN in PD compared to } \\
\text { HC }\end{array}$ \\
\hline Amboni et al., 2015 [99] & $\begin{array}{l}\text { ICA-based analysis (DMN, } \\
\text { FPN, VN) }\end{array}$ & $\begin{array}{l}42 \mathrm{PD}(21 \text { with and } 21 \\
\text { without MCI) vs } 20 \\
\text { HC }\end{array}$ & $\begin{array}{l}\text { Decreased connectivity in bilateral } \\
\text { prefrontal cortex within the FPN in PD with } \\
\text { MCI compared to HC }\end{array}$ \\
\hline Baggio et al., 2015 [104] & $\begin{array}{l}\text { ICA-based connectivity } \\
\text { (DMN, DAN, FPN) }\end{array}$ & $\begin{array}{l}65 \mathrm{PD}(34 \text { with and } 31 \\
\text { without MCI) vs } 38 \\
\text { HC }\end{array}$ & $\begin{array}{l}\text { Decreased connectivity between DAN and } \\
\text { right frontoinsular regions in PD with MCI } \\
\text { compared to HC. Increased connectivity } \\
\text { between DMN and medial and lateral } \\
\text { occipito-parietal regions in PD with MCI } \\
\text { compared to HC. Decreased DAN-DAN, } \\
\text { DMN-DMN and DAN-FPN connectivity, as } \\
\text { well as loss of normal DAN-DMN } \\
\text { anticorrelation in PD with MCI compared to } \\
\text { HC }\end{array}$ \\
\hline Chen et al., 2015 [103] & $\begin{array}{l}\text { Seed-based analysis (bilateral } \\
\text { PCC) }\end{array}$ & $\begin{array}{l}30 \mathrm{PD} \text { ( } 11 \text { with and } 19 \\
\text { without dementia) vs } \\
21 \mathrm{HC}\end{array}$ & $\begin{array}{l}\text { Decreased posterior cingulate cortex } \\
\text { connectivity with the right medial temporal } \\
\text { lobe in PD compared to HC. Decreased } \\
\text { posterior cingulate cortex connectivity with } \\
\text { right parahippocampal region in PD with } \\
\text { dementia compared to those without }\end{array}$ \\
\hline Putcha et al., 2015 [21] & $\begin{array}{l}\text { ICA-based analysis (DMN, } \\
\text { CEN, SN) }\end{array}$ & $\begin{array}{l}24 \mathrm{PD} \text { patients vs } 20 \\
\mathrm{HC}\end{array}$ & $\begin{array}{l}\text { Decreased SN-CEN coupling and increased } \\
\text { DMN-CEN coupling in PD compared to HC }\end{array}$ \\
\hline $\begin{array}{l}\text { Díez-Cirarda et al., } 2018 \\
\text { [100] }\end{array}$ & $\begin{array}{l}\text { ICA-based analysis } \\
\text { (subcortical, AN, SMN, VN, } \\
\text { cognitive-control, DMN and } \\
\text { cerebellar network); } \\
\text { graph-analysis }\end{array}$ & $\begin{array}{l}35 \mathrm{PD}(23 \text { with and } 12 \\
\text { without MCI) vs } 26 \\
\text { HC }\end{array}$ & $\begin{array}{l}\text { Decreased dynamic connectivity in PD with } \\
\text { MCI compared to HC. Decreased } \\
\text { inter-network connectivity between the } \\
\text { SMN-central control, SMN-VN, SMN-AN, } \\
\text { central-control-VN and subcortical-DMN in } \\
\text { PD with MCI compared to HC }\end{array}$ \\
\hline Zhan et al., 2018 [101] & $\begin{array}{l}\text { Seed-based analysis (bilateral } \\
\text { posterior cingulate cortex) }\end{array}$ & $\begin{array}{l}27 \text { PD ( } 9 \text { with and } 9 \\
\text { without MCI vs } 9 \text { with } \\
\text { dementia) vs } 9 \text { HC }\end{array}$ & $\begin{array}{l}\text { Increased posterior cingulate cortex } \\
\text { connectivity in PD with MCI patients and } \\
\text { decreased posterior cingulate cortex } \\
\text { connectivity in PD with dementia compared } \\
\text { to HC. Increased connectivity between } \\
\text { prefrontal cortices and posterior cerebellum } \\
\text { in PD with dementia compared to HC }\end{array}$ \\
\hline
\end{tabular}


Table 1

(continued)

\begin{tabular}{|c|c|c|}
\hline Lopes et al., 2017 [26] & Graph-analysis & $\begin{array}{l}119 \text { PD patients ( } 31 \\
\text { cognitively } \\
\text { unimpaired vs } 31 \text { with } \\
\text { slight mental slowing } \\
\text { vs } 43 \text { with mild to } \\
\text { moderate deficits } \\
\text { mainly in executive } \\
\text { functions vs } 14 \\
\text { patients with severe } \\
\text { deficits in all } \\
\text { cognitive domains }\end{array}$ \\
\hline
\end{tabular}

\begin{tabular}{lll}
\hline Skidmore et al., 2013 [90] $\quad$ ALFF analysis & 15 PD & $\begin{array}{l}\text { Apathy severity is correlated with } \\
\text { connectivity in the left supplementary motor } \\
\text { cortex, the right orbitofrontal cortex, and the }\end{array}$
\end{tabular}
right middle frontal cortex. Depression severity is correlated with connectivity in the right subgenual cingulate

\begin{tabular}{lll}
\hline Baggio et al., 2015 [89] & $\begin{array}{l}\text { Seed-based analysis (limbic, } \\
\text { executive, rostral motor, and } \\
\text { caudal motor regions) }\end{array}$ & $\begin{array}{l}\text { 62 PD (25 with vs 37 } \\
\text { without apathy) vs 31 } \\
\text { HC }\end{array}$ \\
\hline Tessitore et al., 2016 [92] & $\begin{array}{l}\text { ICA-based analysis (DMN, } \\
\text { FPN, SN, SMN, VS, AN) }\end{array}$ & $\begin{array}{l}\text { 40 PD (20 with vs 20 } \\
\text { without distressing } \\
\text { fatigue) vs 20 HC }\end{array}$
\end{tabular}
Decreased connectivity in limbic striatal and frontal regions in $\mathrm{PD}$ patients with apathy compared to those without and HC cognitive impairment worsened. Between-group differences in functional connectivity mainly within the ventral prefrontal, parietal, temporal and occipital cortices as well as the basal ganglia Decreased connectivity in the SMA within the SMN as well as increased connectivity in the prefrontal and posterior cingulate cortices within the DMN in PD patients with fatigue compared to those without

\begin{tabular}{lll}
\hline Su et al., 2015 [80] & $\begin{array}{l}\text { ReHo analysis (left rectal } \\
\text { gyrus, orbitofrontal cortex, } \\
\text { superior temporal pole, } \\
\text { posterior cingulate cortex, } \\
\text { right insula, amygdala) }\end{array}$ & $\begin{array}{l}\text { 54 PD (38 with vs 16 } \\
\text { without hyposmia) vs } \\
\text { 22 HC }\end{array}$ \\
& & \\
\hline $\begin{array}{l}\text { Yoneyama et al., 2018 } \\
{[81]}\end{array}$ & $\begin{array}{l}\text { ICA-based (CEN, DMN, SN, } \\
\text { VN) and seed-based analysis } \\
\text { (amygdala) }\end{array}$ & $\begin{array}{l}\text { 30 PD (15 with and 15 } \\
\text { without hyposmia) vs } \\
15 \text { HC }\end{array}$ \\
& &
\end{tabular}
Decreased connectivity in olfactory regions (i.e., amygdala, olfactory gyrus, orbital frontal cortex, parahippocampal gyrus and insula) as well as increased connectivity in the left anterior/posterior cingulate cortex in $\mathrm{PD}$ with hyposmia compared to those without

Decreased connectivity between amygdala and olfactory cortices in PD with hyposmia compared to $\mathrm{HC}$; increased connectivity within the CEN, SN and VN in PD patients with hyposmia compared to HC

\begin{tabular}{llll}
\hline Wen et al., 2013 [84] & ALFF analysis & $\begin{array}{l}\text { 33 PD (17 with vs 16 } \\
\text { without depression) } \\
\text { vs 21 HC }\end{array}$ & $\begin{array}{l}\text { Decreased connectivity in the DLPFC, } \\
\text { ventromedial prefrontal and the rostral } \\
\text { anterior cingulated cortices in PD with } \\
\text { depression compared to those without }\end{array}$ \\
\hline Sheng et al., 2014 [87] & $\begin{array}{l}\text { ReHo analysis (left middle } \\
\text { frontal gyrus, right inferior } \\
\text { frontal gyrus, left amygdala } \\
\text { and bilateral lingual gyrus) }\end{array}$ & $\begin{array}{l}41 \text { PD (20 with vs 21 } \\
\text { without depression) } \\
\text { vs 25 HC }\end{array}$ & $\begin{array}{l}\text { Increased connectivity in the left middle } \\
\text { frontal gyrus and right inferior frontal gyrus } \\
\text { as well as decreased connectivity in the left } \\
\text { amygdala and bilateral lingual gyrus in PD } \\
\text { with depression compared to those without }\end{array}$ \\
\hline Lou et al., 2015 [83] & Eigenvector centrality & $\begin{array}{l}34 \text { PD (17 with vs 17 } \\
\text { without depression) }\end{array}$ & $\begin{array}{l}\text { Decreased connectivity in the left DLPFC } \\
\text { and right superior temporal gyrus as well as } \\
\text { increased connectivity in the right posterior } \\
\text { cingulate cortex, in PD with depression } \\
\text { compared to those without }\end{array}$ \\
\hline Hu et al., 2015 [88] & $\begin{array}{l}\text { Seed-based analysis } \\
\text { (amygdala) }\end{array}$ & $\begin{array}{l}60 \text { PD (20 with vs } 40 \\
\text { without depression) }\end{array}$ & $\begin{array}{l}\text { Increased connectivity between left } \\
\text { amygdala and bilateral mediodorsal } \\
\text { thalamus as well as increased connectivity } \\
\text { between right amygdala and left superior } \\
\text { temporal gyrus and left calcarine gyrus in PD } \\
\text { with depression compared to those without }\end{array}$ \\
\hline
\end{tabular}


Table 1

(continued)

\begin{tabular}{llll}
\hline & \multicolumn{2}{c}{ Levodopa-induced dyskinesias } \\
\hline Cerasa et al., 2015 106] & $\begin{array}{l}\text { Seed-based analysis (right } \\
\text { inferior frontal cortex) }\end{array}$ & $\begin{array}{l}\text { 24 PD (12 with vs 12 } \\
\text { without LID) }\end{array}$ & $\begin{array}{l}\text { Decreased connectivity of the right inferior } \\
\text { frontal cortex with the left motor cortex as } \\
\text { well as increased connectivity with the right } \\
\text { putamen in PD with LID compared to those } \\
\text { without }\end{array}$ \\
\hline Herz et al., 2016 [107] & $\begin{array}{l}\text { Seed-based analysis (bilateral } \\
\text { putamen, M1, SMA and } \\
\text { preSMA, right inferior frontal } \\
\text { cortex) }\end{array}$ & $\begin{array}{l}\text { 24 PD (12 with vs 12 } \\
\text { without LID) }\end{array}$ & $\begin{array}{l}\text { Dopaminergic modulation of connectivity } \\
\text { between the putamen and primary } \\
\text { sensorimotor cortex predicted LID } \\
\text { development with a specificity of 100\% and }\end{array}$ \\
& & & a sensitivity of 91\%
\end{tabular}

PD, Parkinson's disease; AD, Alzheimer's disease; HC, healthy controls; DMN, default-mode network; FPN, frontoparietal network; SN, salience network; CEN, central executive network; DAN, dorsal attention network; SMN, sensorimotor network; VN, visual network; AN: auditory network; BGN, basal ganglia network; ICA, independent component analysis; ALFF, amplitude of the low frequency fluctuations; ReHo, regional homogeneity; ROI, region of interest; STN, subthalamic nucleus; SMA, supplementary motor area; M1, primary motor cortex; DLPFC, dorsolateral prefrontal cortex; TD, tremor-dominant; PIGD, postural instability and gait difficulty; FOG, freezing of gait; MCI, mild cognitive impairment; LID, levodopa-induced dyskinesias; iRBD, idiopathic REM behavioral disorders.

\section{DIAGNOSIS OF PD AND MOTOR SYMPTOMS CORRELATES}

Paralleling the neuropathological progression of PD, RS-fMRI changes (both increase and decrease functional connectivity) involving the dopaminergic cortico-striatal and mesolimbic-striatal loops have been consistently detected in PD patients [20], providing a valuable contribution to the comprehension of the pathopsysiological mechanisms underlying motor symptoms in PD.

A recent meta-analysis [36], revealed that a decreased functional connectivity within the posterior putamen is the most consistent finding across different RS-fMRI studies in PD patients, with a progressive correlation with symptoms severity. This subcortical area and its cortical projections are engaged in a functional network which has been shown to be modulated by levodopa administration [36, 37].

A method to map functional connectivity within the basal ganglia (i.e., basal ganglia network, BGN) has been developed using a BGN template derived from 80 elderly controls [38, 39]. Patients with PD showed a reduced functional connectivity in a wide range of BGN areas (such as putamen, caudate, anterior thalamus, dorsolateral prefrontal cortex and precuneus). Average BGN connectivity was able to differentiate patients with PD from controls with $100 \%$ sensitivity and $89.5 \%$ specificity [39]. However, in a following study [40] the BGN connectivity was not able to differentiate subjects with idiopathic REM sleep behavior disorder (iRBD) from PD patients, thereby limiting the potential role of this network as a diagnostic biomarker in PD patients (more details below).

At a cortical level, a decreased functional connectivity within the SMA, a cortical area linked to motor preparation and initiation [41], has been consistently found in PD patients compared to healthy controls at different disease stages [42-46]. Some studies also demonstrated an increased RS functional connectivity within the primary motor cortex (M1) in PD patients [43]. Even though decreased connectivity may be straightforward associated to loss of neural function, it is important to note that increased connectivity has also pathologic connotations. First, increased connectivity may be compensatory, representing a network response to local neuronal injury that allows for the maintenance of the same global performance. Second, what we see as "hyperconnected" may be underlined by the loss of networks dynamic properties to shift between different states (i.e., from a "hyper-" to a "hypo-connected" state).

In a cohort of drug-naïve PD patients, we performed an ICA-based RS-fMRI study and demonstrated the presence of specific SMN connectivity changes when compared to healthy controls, which were partially restored by the first levodopa administration [44]. Moreover, a ROI analysis of the SMN functional connectivity within the basal ganglia and thalamus revealed that levodopa significantly increases the participation of these subcortical regions to the SMN activity. This is consistent with several studies showing a specific levodopa modulation of the cortico-striatal functional connec- 
tivity occurring in parallel with motor symptoms improvement [36, 37].

Interestingly, no statistically significant connectivity changes were detected in drug-naïve PD patients compared to controls within the M1, confirming that the compensatory functional reorganization of this area, previously reported, may be related to a prolonged dopaminergic treatment rather than to PD per se [44]. Moreover, in the same report no grey matter atrophy was detected in PD patients, suggesting that functional connectivity abnormalities may arise even before brain structural changes become evident. This suggests that RS-fMRI may be used as a biomarker of early cortical-subcortical functional aberrant phenomena potentially following initial neuropathological PD-related changes.

In this framework, it is interesting that SMN connectivity abnormalities in the absence of structural changes were also detected in asymptomatic LRRK2 (G2019S) mutation carriers, suggesting that functional changes may occur also during the preclinical phase of the disease (see below for further details) [47, 48].

In summary, functional connectivity changes involving the cortico-striatal pathway have been consistently shown in PD patients, with a clinical correlation with symptoms severity and a specific sensitivity to levodopa stimulation, suggesting that: 1) functional disruption within this network and all across its hubs may be considered as a correlate of the neuropathological process underlying PD and symptoms development, 2) this functional architecture may be potentially used as a biomarker of treatment response throughout the disease course.

Longitudinal studies are warranted to support this hypothesis. Along this research line, Manza and colleagues [49] seeded the striatum and its subdivisions in a cohort of early PD patients to characterize the pattern of functional disconnection occurring over 1 year. Their data revealed that motor symptoms progression is related to an increasing functional decoupling between anterior putamen and midbrain. This is consistent with previous findings in advanced PD patients also exhibiting a functional decoupling between striatum and midbrain regions when compared to controls [50], further supporting the role of RS-fMRI to mark disease progression of PD.

Another longitudinal study showed that an increased connectivity between cerebellum and the sensorimotor cortex is present at baseline and parallels with motor outcome deterioration in a cohort of early PD patients at 1.5-year follow-up [51]. Previous reports revealed an increased connectivity within the cerebellum in PD patients compared to controls [43, 52] as well as an impaired functional communication between cerebellum and other SMN areas [52]. This pattern has been interpreted as compensatory, but it should be noted that the role of chronic dopaminergic treatment has been also involved in the development of aberrant functional connectivity response within the cerebellum $[53,54]$.

In summary, at this point functional connectivity changes within the cerebellum may potentially support the clinical diagnosis of PD but they cannot be considered as a reliable biomarker to track PD progression over time.

Changes within non-motor RSNs and areas have been also found in PD patients compared to controls. Indeed, a recent meta-analysis merging RS-fMRI data from 854 PD patients and 831 controls, found that an increased functional connectivity within the post-central gyrus is the most consistent finding across studies, with a cross-validation in an independent dataset [55]. Similarly, another meta-analysis found convergent evidence for intrinsic functional disturbances in bilateral inferior parietal lobule in PD patients compared to healthy controls [56]. The potential role of the parietal cortex to monitor disease progression is suggested in a graph-analysis study, wherein topological global and nodal feature of the functional connectome were extracted in a large cohort of PD patients, across different disease stages [27]. This study showed that the nodal centralities in the left post-central gyrus were correlated with motor outcome and progressed along with disease stage [28].

Non-motor RSNs changes were also revealed by comparing different PD motor phenotypes. Indeed, a decreased functional connectivity within the DMN has been revealed in cognitively unimpaired akineticdominant PD patients compared to both tremor dominant patients and controls [57, 58], confirming that different motor phenotypes may be related to a distinctive underlying pathophysiology, coupled with a divergent risk profile for the development of cognitive impairment [59, 60]. In this framework, the presence of freezing of gait, which is considered a clinical biomarker of worse disease progression and earlier development of cognitive impairment, has been consistently associated with specific involvement of cognition and attentionrelated RSNs, encompassing frontal, parietal and temporo-occipital areas [61-63]. 


\section{PREMOTOR PHASE AND NON-MOTOR SYMPTOMS CORRELATES}

As neuroprotective treatment in early stages could prevent clinical PD from emerging, in the last years a great deal of effort has been gone in the identification of clinical and pre-clinical aspects, timing and risk of PD development. To this aim, a dedicated Task Force of The International Parkinson and Movement Disorder Society, has released proposed criteria for prodromal PD [2]. However, to date only a few studies have been focused on RS-fMRI signatures of subjects at clear risk to develop PD.

RBD is characterized by loss of the normal atonia during REM sleep [64]. RBD has shown an incomparable potential as a prodromal PD marker, with an estimated period of 10-15 years of progressive neuronal loss before the onset of the core motor symptoms [65]. Therefore, in the last years several studies have investigated neural correlates of $\mathrm{iRBD}$ with a high risk of progression in PD [66-71]. A few studies have addressed functional connectivity changes in patients with iRBD. The first one [72], using a seedbased approach, has revealed an altered nigrostriatal connectivity pattern in patients with iRBD. A more recent one [40], has shown that BGN connectivity measures may differentiate both iRBD and PD from controls. These results clearly demonstrate that a disrupted functional connectivity within motor regions may be detected in iRBD even before the development of motor symptoms. However, it is important to note that in the same study 123I-ioflupane single photon emission computerized tomography was able to differentiate iRBD from PD patients whereas BGN connectivity did not, and this could limit the robustness of findings [40].

Healthy carriers of the G2019S LRRK2 mutation represent an interesting human model of premotor PD. Indeed, PD LRRK2 parkinsonism is associated with Lewy body pathology and with similar clinical signs as idiopathic PD [73]. Presence of LRRK2 G2019S mutation is associated with a markedly increased, age-dependent risk of developing PD [73] with a penetrance estimations ranging from $10 \%-17 \%$ at the age 50 years to $25 \%-85 \%$ at the age of 70 years [73]. Recently, a seed-based RSfMRI study revealed that the right inferior parietal cortex had a reduced connectivity with the posterior putamen and an increased connectivity with the anterior putamen in LRRK2 G2019S mutation carriers compared with noncarriers [47]. Similarly, in early-stage PD patients, presence of a shift in corti- costriatal connectivity from severely affected striatal regions (posterior putamen) to less affected striatal regions (anterior putamen) with a potential compensatory role has been highlighted [49]. More recently, asymptomatic LRRK2 mutation carriers showed RS functional connectivity changes in striatocortical and nigrocortical circuits compared with noncarriers [48]. These findings support the concept that an altered cortico-nigro-striatal connectivity may precedes clinical symptoms onset, at least in genetic forms of $\mathrm{PD}$, and may be potentially proposed as a early biomarker of the neurodegeneration process leading to PD development.

Evidence from neuropathological studies [74, 75] have shown that noradrenergic, serotonergic and cholinergic pathways are severely affected by neurodegenerative processes during the prodromal stage of $\mathrm{PD}$, prior to substantia nigra degeneration [75]. Alteration of non-dopaminergic pathways has been detected as an underlying correlate of several nonmotor symptoms in PD, which may characterize the prodromal disease stage. Thus, functional connectivity correlates of non-motor symptoms, even when studied in patients with a clinical diagnosis of PD, may provide interesting suggestions about early disease spreading processes and pathways to be targeted with novel treatments.

Hyposmia is a well-established and early nonmotor symptom of PD [76, 77]. Several studies have suggested its role as a potential biomarker of PD progression and cognitive decline [79]. To date, only a few studies have assessed neural correlates of hyposmia in PD patients $[80,81]$. In one study [80] PD patients with hyposmia, compared with those without hyposmia, showed a decreased functional connectivity within both olfactory and non-olfactory related cortical areas and an increased functional connectivity in the left anterior/posterior cingulate cortex, with a potential PD-pathology-related compensatory role. A more recent study [81] showed that hyposmia is associated with a decreased functional connectivity within the limbic/paralimbic system and between amygdala and parietal/occipital areas, which was correlated with hyposmia severity.

Depression in PD may be considered as an interface between emotional processing and cognitive functions [82]. Indeed, using different RS-fMRI approaches, an intrinsic dysfunction within the dorsolateral prefrontal cortex in depressed PD (dPD) patients has been observed [83, 84]. This cortical area has a pivotal role in the prefrontal-limbic network, and is also involved in cognition and executive 
functions [85, 86]. Moreover, two RS-fMRI studies has emphasized the role of the amygdala in mood modulation, revealing an abnormal connectivity within this area in dPD patients [87, 88]. Whereas, the presence of apathy in PD has been associated with a disrupted functional connectivity in frontostriatal pathways $[89,90]$, mainly involving its limbic components. Fatigue is a common and disabling non-motor symptom in PD patients [91]. A recent RS-fMRI study [92] has revealed that fatigue is associated with a divergent pattern of functional connectivity within SMN and DMN in drug-naïve PD patients. Moreover, fatigue severity was correlated with these connectivity changes, suggesting that an efficient functional interplay between these cortical areas might be necessary to maintain a good motor performance without development of fatigue.

In recent years, an intrinsic aberrant functional connectivity within the DMN has been implicated in cognitive processing in several neurodegenerative disorders [93-95]. A recent meta-analysis showed that decreased functional connectivity within the DMN is the most consistent finding able to differentiate PD patients with and without cognitive impairment [96]. In a cohort of early-stage cognitively unimpaired patients with PD, we demonstrated the presence of a decreased medial temporal and inferior parietal connectivity within the DMN, which was correlated with cognitive performances [97]. This finding suggests that functional disconnection of posterior brain regions can precede clinically measurable cognitive impairment in PD. Interestingly, functional connectivity deterioration in posterior cortical regions has been associated with progression of cognitive impairment over 3 years in a longitudinal fMRI study [98]. Moreover, alterations within the DMN have been shown to be more relevant in PD patients with MCI [99-101] and with dementia [97, 101-103], further supporting the potential role of RS-fMRI to depict a sensitive and specific biomarker of dementia in PD for prognostic and disease-monitoring purposes.

Together with the DMN, other important neurocognitive RSNs have been found to be correlated with cognitive deficits in PD, such as the DAN, CEN, SN and associate visual networks [21, 98, 99, 104] and an efficient inter-network connectivity between these networks is relevant, as well [21,22]. This is consistent with the hypothesis that two different patterns of cognitive impairment may generally occur in patients with PD: an anterior, frontostriatal executive syndrome, more common in early disease and with a low rate of evolution in dementia, and a more posterior cortical syndrome, which has been related to worse cognitive prognosis over time [105]. In this framework, application of RS-fMRI measures may allow to detect those patients early presenting with a functional architecture more frequently associated with cognitive impairment and stratify the risk of developing dementia over time.

\section{LEVODOPA-INDUCED DYSKINESIAS}

LID represents a major debilitating side effect of long-term DRT in PD. To date, these complications have been assessed by means of fMRI task-based studies [6]. Only two studies focused on intrinsic functional connectivity correlates of LID [106, 107]. In details, functional connectivity was assessed in a RS-fMRI study centering the right inferior frontal cortex, a cortical area critically involved in motor control and inhibition, in PD patients with LID compared with those without [106]. The study revealed that connectivity of the right inferior frontal cortex is decreased with the left motor cortex and increased with the right putamen in patients with LID when switching from the OFF to the ON phase of levodopa treatment. Moreover, the degree of such alteration correlated with motor disability. Interestingly, the Authors performed an additional and independent experiment, applying different forms of repetitive transcranial magnetic stimulation over the right inferior frontal cortex in a new group of dyskinetic PD patients who were taking a supramaximal dose of levodopa, which were able to reduce the amount of hyperkinetic movements [106]. Together with evidence from other task-based fMRI as well as corticometric studies [108], this study suggests that this area may play a key role in controlling the development of LID. These data were not confirmed in a more recent study by Herz and coll. [107], which analyzed levodopa-induced modulation of cortico-striatal resting-state connectivity between the putamen and three cortical ROIs: SMA, primary sensorimotor cortex, and right inferior frontal gyrus. Indeed, no interaction has been found between modulation of the right inferior frontal gyrus/putamen connectivity and LID development and severity. However, dopaminergic modulation of RS connectivity between the putamen and primary sensorimotor cortex in the most affected hemisphere predicted whether patients would develop LID with a specificity of $100 \%$ and a sensitivity of $91 \%$. Moreover, 
the levodopa modulation of RS connectivity between the SMA and putamen was able to predict LID severity. These apparently divergent results may stem from methodological and design discrepancies between the two studies. Nevertheless, both these studies suggest that levodopa intake may interfere with the physiological organization of the cortico-putaminal connectivity in LID patients. However, it is not yet clear whether this network reorganization is related to chronic DRT or may be considered as a premorbid pattern predisposing to LID development. Prospective and longitudinal studies are still lacking and should be specifically designed to determine the role of RS-fMRI to predict LID development over time.

\section{CONCLUSION}

Overall, RS-fMRI literature supports that an aberrant functional interplay within corticostriatal loops may characterize PD patients from controls. These functional abnormalities have been detected both in the early stage of the disease and in subjects at high risk to develop clinical established PD and may be potentially proposed as early biomarkers to track PDrelated neurodegeneration pathway. Moreover, a few studies comparing different PD stages and applying longitudinal designs showed potential compensatory effects and treatment-related changes which may arise throughout the disease progression, and also detected intrinsic brain connectivity signatures to be targeted for prediction and neuroprotection purposes. However, development of reproducible and clinically useful RS-fMRI imaging biomarkers of PD is needed to overcome some inconsistencies between studies, mainly related to the complexity of the disease.

\section{CONFLICT OF INTEREST}

The authors have no conflict of interest to report.

\section{REFERENCES}

[1] de Lau LM, Breteler MM (2006) Epidemiology of Parkinson's disease. Lancet Neurol 5, 525-535.

[2] Berg D, Postuma RB, Bloem B, Chan P, Dubois B, Gasser T, Goetz CG, Halliday GM, Hardy J, Lang AE, Litvan I, Marek K, Obeso J, Oertel W, Olanow CW, Poewe W, Stern M, Deuschl G (2014) Time to redefine PD? Introductory statement of the MDS Task Force on the definition of Parkinson's disease. Mov Disord 29, 454-462.

[3] Postuma RB, Berg D, Stern M, Poewe W, Olanow CW, Oertel W, Obeso J, Marek K, Litvan I, Lang AE, Halliday G, Goetz CG, Gasser T, Dubois B, Chan P, Bloem BR,
Adler CH, Deuschl G (2013) MDS clinical diagnostic criteria for Parkinson's disease. Mov Disord 30, 1591-1601.

[4] Salat D, Tolosa E (2013) Levodopa in the treatment of Parkinson's disease: Current status and new developments. J Parkinsons Dis 3, 255-269.

[5] Kalia LV, Lang AE (2015) Parkinson's disease. Lancet 386, 896-912.

[6] Bastide MF, Meissner WG, Picconi B, Fasano S, Fernagut PO, Feyder M, Francardo V, Alcacer C, Ding Y, Brambilla R, Fisone G, Jon Stoessl A, Bourdenx M, Engeln M, Navailles S, De Deurwaerdére P, Ko WK, Simola N, Morelli M, Groc L, Rodriguez MC, Gurevich EV, Quik M, Morari M, Mellone M, Gardoni F, Tronci E, Guehl D, Tison F, Crossman AR, Kang UJ, Steece-Collier K, Fox S, Carta M, Angela Cenci M, Bézard E (2015) Pathophysiology of L-dopa-induced motor and non-motor complications in Parkinson's disease. Prog Neurobiol 132, 96-168.

[7] Hauser RA, Rascol O, Korczyn AD, Jon Stoessl A, Watts RL, Poewe W, De Deyn PP, Lang AE (2007) Ten-year follow-up of Parkinson's disease patients randomized to initial therapy with ropinirole or levodopa. Mov Disord 22, 2409-2417.

[8] Muslimovic D, Post B, Speelman JD, de Haan RJ, Schmand B (2009) Cognitive decline in Parkinson's disease: A prospective longitudinal study. J Int Neuropsychol Soc 15, 426-437.

[9] Fengler S, Liepelt-Scarfone I, Brockmann K, Schäffer E, Berg D, Kalbe E (2017) Cognitive changes in prodromal Parkinson's disease: A review. Mov Disord 32, 16551666.

[10] Hely MA, Reid WG, Adena MA, Halliday GM, Morris JG (2008) The Sydney multicenter study of Parkinson's disease: The inevitability of dementia at 20 years. Mov Disord 23, 837-844.

[11] Friston KJ, Holmes AP, Poline JB, Grasby PJ, Williams SC, Frackowiak RS, Turner R (1995) Analysis of fMRI time-series revisited. Neuroimage 2, 45-53.

[12] Logothetis NK, Wandell BA (2004) Interpreting the BOLD signal. Annu Rev Physiol 66, 735-769.

[13] Biswal B, Yetkin FZ, Haughton VM, Hyde JS (1995) Functional connectivity in the motor cortex of resting human brain using echo-planar MRI. Magn Reson Med 34, 537-541.

[14] Fox MD, Raichle ME (2007) Spontaneous fluctuations in brain activity observed with functional magnetic resonance imaging. Nat Rev Neurosci 8, 700-711.

[15] Deco G, Jirsa VK, McIntosh AR (2011) Emerging concepts for the dynamical organization of resting-state activity in the brain. Nat Rev Neurosci 12, 43-56.

[16] Zuo XN, Di Martino A, Kelly C, Shehzad ZE, Gee DG, Klein DF, Castellanos FX, Biswal BB, Milham MP (2010) The oscillating brain: Complex and reliable. Neuroimage 49, 1432-1445.

[17] Lee MH, Smyser CD, Shimony JS (2013) Resting-state fMRI: A review of methods and clinical applications. AJNR Am J Neuroradiol 34, 1866-1872.

[18] Smitha KA, Akhil Raja K, Arun KM, Rajesh PG, Thomas B, Kapilamoorthy TR, Kesavadas C (2017) Resting state fMRI: A review on methods in resting state connectivity analysis and resting state networks. Neuroradiol J 30, 305317.

[19] Hyvarinen A, Karhunen J, Oja E (2001) Independent component analysis. New York: John Wiley \& Sons, Inc. 
[20] Filippi M, Elisabetta S, Piramide N, Agosta F (2018) Functional MRI in idiopathic Parkinson's disease. Int Rev Neurobiol 141, 439-467.

[21] Putcha D, Ross RS, Cronin-Golomb A, Janes AC, Stern CE (2015) Altered intrinsic functional coupling between core neurocognitive networks in Parkinson's disease. $\mathrm{Neu}$ roimage Clin 7, 449-455.

[22] Putcha D, Ross RS, Cronin-Golomb A, Janes AC, Stern CE (2016) Salience and default mode network coupling predicts cognition in aging and Parkinson's disease. J Int Neuropsychol Soc 22, 205-215.

[23] Menon V (2011) Large-scale brain networks and psychopathology: A unifying triple network model. Trends Cogn Sci 15, 483-506.

[24] Sang L, Zhang J, Wang L, Zhang J, Zhang Y, Li P, Wang J, Qiu M (2015) Alteration of brain functional networks in early-stage Parkinson's disease: A resting-state fMRI study. PLoS One 10, e0141815.

[25] Berman BD, Smucny J, Wylie KP, Shelton E, Kronberg E, Leehey M, Tregellas JR (2016) Levodopa modulates small-world architecture of functional brain networks in Parkinson's disease. Mov Disord 31, 1676-1684.

[26] Lopes R, Delmaire C, Defebvre L, Moonen AJ, Duits AA, Hofman P, Leentjens AF, Dujardin K (2017) Cognitive phenotypes in Parkinson's disease differ in terms of brainnetwork organization and connectivity. Hum Brain Mapp 38, 1604-1621.

[27] Fang J, Chen H, Cao Z, Jiang Y, Ma L, Ma H, Feng T (2017) Impaired brain network architecture in newly diagnosed Parkinson's disease based on graph theoretical analysis. Neurosci Lett 657, 151-158.

[28] Suo X, Lei D, Li N, Cheng L, Chen F, Wang M, Kemp GJ, Peng R, Gong Q (2017) Functional brain connectome and its relation to Hoehn and Yahr stage in Parkinson disease. Radiology 285, 904-913.

[29] Ma LY, Chen XD, He Y, Ma HZ, Feng T (2017) Disrupted brain network hubs in subtype-specific Parkinson's disease. Eur Neurol 78, 200-209.

[30] de Schipper LJ, Hafkemeijer A, van der Grond J, Marinus J, Henselmans JML, van Hilten JJ (2018) Altered whole-brain and network-based functional connectivity in Parkinson's disease. Front Neurol 9, 419.

[31] Hou Y, Wei Q, Ou R, Yang J, Song W, Gong Q, Shang H (2018) Impaired topographic organization in cognitively unimpaired drug-naïve patients with rigidity-dominant Parkinson's disease. Parkinsonism Relat Disord 56, 52-57.

[32] Badea L, Onu M, Wu T, Roceanu A, Bajenaru O (2017) Exploring the reproducibility of functional connectivity alterations in Parkinson's disease. PLoS One 12, 0188196.

[33] O'Connor EE, Zeffiro TA (2019) Why is clinical fMRI in a resting state? Front Neurol 10, 420.

[34] Gordon EM, Laumann TO, Adeyemo B, Gilmore AW, Nelson SM, Dosenbach NUF, Petersen SE (2017) Individual-specific features of brain systems identified with resting state functional correlations. Neuroimage 146 , 918-939.

[35] Liu W, Wei D, Chen Q, Yang W, Meng J, Wu G, Bi T, Zhang Q, Zuo XN, Qiu J (2017) Longitudinal test-retest neuroimaging data from healthy young adults in southwest China. Sci Data 4, 170017.

[36] Herz DM, Eickhoff SB, Lokkegaard A, Siebner HR (2014) Functional neuroimaging of motor control in Parkinson's disease: A meta-analysis. Hum Brain Mapp 35, 32273237.
[37] Tahmasian M, Bettray LM, van Eimeren T, Drzezga A, Timmermann L, Eickhoff CR, Eickhoff SB, Eggers C (2015) A systematic review on the applications of resting-state fMRI in Parkinson's disease: Does dopamine replacement therapy play a role? Cortex $\mathbf{7 3}, 80-105$.

[38] Rolinski M, Griffanti L, Szewczyk-Krolikowski K, Menke RA, Wilcock GK, Filippini N, Zamboni G, Hu MT, Mackay CE (2015) Aberrant functional connectivity within the basal ganglia of patients with Parkinson's disease. Neuroimage Clin 9, 126-132.

[39] Szewczyk-Krolikowski K, Menke RA, Rolinski M, Duff E, Salimi-Khorshidi G, Filippini N, Zamboni G, Hu MT, Mackay CE (2014) Functional connectivity in the basal ganglia network differentiates PD patients from controls. Neurology 83, 208-214.

[40] Rolinski M, Griffanti L, Piccini P, Roussakis AA, Szewczyk-Krolikowski K, Menke RA, Quinnell T, Zaiwalla Z, Klein JC, Mackay CE, Hu MT (2016) Basal ganglia dysfunction in idiopathic REM sleep behaviour disorder parallels that in early Parkinson's disease. Brain 139, 2224-2234.

[41] Nachev P, Kennard C, Husain M (2008) Functional role of the supplementary and pre-supplementary motor areas. Nat Rev Neurosci 9, 856-869.

[42] Wu T, Wang L, Chen Y, Zhao C, Li K, Chan P (2009) Changes of functional connectivity of the motor network in the resting state in Parkinson's disease. Neurosci Lett 21, 466.

[43] Wu T, Long X, Wang L, Hallett M, Zang Y, Li K, Chan P (2011) Functional connectivity of cortical motor areas in the resting state in Parkinson's disease. Hum Brain Mapp 32, 1443-5710.

[44] Esposito F, Tessitore A, Giordano A, De Micco R, Paccone A, Conforti R, Pignataro G, Annunziato L, Tedeschi G (2013) Rhythm-specific modulation of the sensorimotor network in drug-naive patients with Parkinson's disease by levodopa. Brain 136, 710-725.

[45] Agosta F, Caso F, Stankovic I, Inuggi A, Petrovic I, Svetel M, Kostic VS, Filippi M (2014) Cortico-striatal-thalamic network functional connectivity in hemiparkinsonism. Neurobiol Aging 35, 2592-2602.

[46] Baudrexel S, Witte T, Seifried C, von Wegner F, Beissner F, Klein JC, Steinmetz H, Deichmann R, Roeper J, Hilker R (2011) Resting state fMRI reveals increased subthalamic nucleus-motor cortex connectivity in Parkinson's disease. Neuroimage 55, 1728-1738.

[47] Helmich RC, Thaler A, van Nuenen BF, Gurevich T, Mirelman A, Marder KS, Bressman S, Orr-Urtreger A, Giladi N, Bloem BR, Toni I; LRRK2 Ashkenazi Jewish Consortium (2015) Reorganization of corticostriatal circuits in healthy G2019S LRRK2 carriers. Neurology 84, 399-406.

[48] Vilas D, Segura B, Baggio HC, Pont-Sunyer C, Compta Y, Valldeoriola F, José Martí M, Quintana M, Bayés A, Hernández-Vara J, Calopa M, Aguilar M, Junqué C, Tolosa E; the Barcelona LRRK2 Study Group (2016) Nigral and striatal connectivity alterations in asymptomatic LRRK2 mutation carriers: A magnetic resonance imaging study. Mov Disord 31, 1820-1828.

[49] Manza P, Zhang S, Li CS, Leung HC (2016) Restingstate functional connectivity of the striatum in early-stage Parkinson's disease: Cognitive decline and motor symptomatology. Hum Brain Mapp 37, 648-662.

[50] Hacker CD, Perlmutter JS, Criswell SR, Ances BM, Snyder AZ (2012) Resting state functional connectivity of 
the striatum in Parkinson's disease. Brain 135, 36993711 .

[51] Tuovinen, N, Seppi K, de Pasquale F, Muller C, Nocker M, Schocke M (2018) The reorganization of functional architecture in the early-stages of Parkinson's disease. Parkinsonism Relat Disord 50, 61-68.

[52] Simioni AC, Dagher A, Fellows LK (2017) Effects of levodopa on corticostriatal circuits supporting working memory in Parkinson's disease. Cortex 93, 193-205.

[53] Jech R, Mueller K, Schroeter ML, Růžička E (2013) Levodopa increases functional connectivity in the cerebellum and brainstem in Parkinson's disease. Brain 136, 234.

[54] Mueller K, Jech R, Ballarini T, Holiga Š, Růžička F, Piecha FA, Möller HE, Vymazal J, Růžička E, Schroeter ML (2019) Modulatory effects of levodopa on cerebellar connectivity in Parkinson's disease. Cerebellum 18, 212-224.

[55] Ji GJ, Hu P, Liu TT, Li Y, Chen X, Zhu C, Tian Y, Chen X, Wang K (2018) Functional connectivity of the corticobasal ganglia-thalamocortical network in Parkinson disease: A systematic review and meta-analysis with cross-validation. Radiology 287, 973-982.

[56] Tahmasian M, Eickhoff SB, Giehl K, Schwartz F, Herz DM, Drzezga A, van Eimeren T, Laird AR, Fox PT, Khazaie H, Zarei M, Eggers C, Eickhoff CR (2017) Resting-state functional reorganization in Parkinson's disease: An activation likelihood estimation meta-analysis. Cortex 92, 119-138.

[57] Chen HM, Wang ZJ, Fang JP, Gao LY, Ma LY, Wu T, Hou YN, Zhang JR, Feng T (2015) Different patterns of spontaneous brain activity between tremor-dominant and postural instability/gait difficulty subtypes of Parkinson's disease: A resting-state fMRI study. CNS Neurosci Ther 21, 855-866.

[58] Karunanayaka PR, Lee EY, Lewis MM, Sen S, Eslinger PJ, Yang QX, Huang X (2016) Default mode network differences between rigidity- and tremor-predominant Parkinson's disease. Cortex 81, 239-250.

[59] Eggers C, Pedrosa DJ, Kahraman D, Maier F, Lewis CJ, Fink GR, Schmidt M, Timmermann L (2012) Parkinson subtypes progress; differently in clinical course and imaging pattern. PLoS One 7, 46813.

[60] Lewis MM, Du G, Sen S, Kawaguchi A, Truong Y, Lee S, Mailman RB, Huang X (2011) Differential involvement of striato- and cerebello-thalamo-cortical pathways in tremor- and akinetic/rigid-predominant Parkinson's disease. Neuroscience 177, 230-239.

[61] Tessitore A, Amboni M, Esposito F, Russo A, Picillo M, Marcuccio L, Pellecchia MT, Vitale C, Cirillo M, Tedeschi G, Barone P (2012) Resting-state brain connectivity in patients with Parkinson's disease and freezing of gait. Parkinsonism Relat Disord 18, 781-787.

[62] Fling BW, Cohen RG, Mancini M, Carpenter SD, Fair DA, Nutt JG, Horak FB (2014) Functional reorganization of the locomotor network in Parkinson patients with freezing of gait. PLoS One 9, 100291.

[63] Canu E, Agosta F, Sarasso E, Volonté MA, Basaia S, Stojkovic T, Stefanova E, Comi G, Falini A, Kostic VS, Gatti R, Filippi M (2015) Brain structural and functional connectivity in Parkinson's disease with freezing of gait. Hum Brain Mapp 36, 5064-5078.

[64] Schenck CH, Mahowald MW (2002) REM sleep behavior disorder: Clinical, developmental, and neuroscience perspectives 16 years after its formal identification in SLEEP. Sleep 25, 120-138.
[65] Hawkes CH (2008) The prodromal phase of sporadic Parkinson's disease: Does it exist and if so how long is it? Mov Disord 23, 1799-1807.

[66] Schenck CH, Boeve BF, Mahowald MW (2013) Delayed emergence of a parkinsonian disorder or dementia in $81 \%$ of older males initially diagnosed with idiopathic REM sleep behavior disorder (RBD): 16-year update on a previously reported series. Sleep Med 14, 744-748.

[67] Iranzo A, Tolosa E, Gelpi E, Molinuevo JL, Valldeoriola F, Serradell M, Sanchez-Valle R, Vilaseca I, Lomeña F, Vilas D, Lladó A, Gaig C, Santamaria J (2013) Neurodegenerative disease status and post-mortem pathology in idiopathic rapid-eye-movement sleep behaviour disorder: An observational cohort study. Lancet Neurol 12, 443-453.

[68] Postuma RB, Gagnon JF, Vendette M, Fantini ML, Massicotte-Marquez J, Montplaisir J (2009) Quantifying the risk of neurodegenerative disease in idiopathic REM sleep behavior disorder. Neurology 72, 1296-1300.

[69] Wing YK, Li SX, Mok V, Lam SP, Tsoh J, Chan A, Yu MW, Lau CY, Zhang J, Ho CK (2012) Prospective outcome of rapid eye movement sleep behaviour disorder: Psychiatric disorders as a potential early marker of Parkinson's disease. J Neurol Neurosurg Psychiatry 83, 470-472.

[70] Boot BP, Boeve BF, Roberts RO, Ferman TJ, Geda YE, Pankratz VS, Ivnik RJ, Smith GE, McDade E, Christianson TJ, Knopman DS, Tangalos EG, Silber MH, Petersen RC (2012) Probable rapid eye movement sleep behavior disorder increases risk for mild cognitive impairment and Parkinson disease: A population-based study. Ann Neurol 71, 49-56.

[71] Kalia LV, Lang AE, Hazrati LN, Fujioka S, Wszolek ZK, Dickson DW, Ross OA, Van Deerlin VM, Trojanowski JQ, Hurtig HI, Alcalay RN, Marder KS, Clark LN, Gaig C, Tolosa E, Ruiz-Martínez J, Marti-Masso JF, Ferrer I, López de Munain A, Goldman SM, Schüle B, Langston JW, Aasly JO, Giordana MT, Bonifati V, Puschmann A, Canesi M, Pezzoli G, Maues De Paula A, Hasegawa K, Duyckaerts C, Brice A, Stoessl AJ, Marras C (2015) Clinical correlations with Lewy body pathology in LRRK2-related Parkinson disease. JAMA Neurol 72, 100-105.

[72] Ellmore TM, Castriotta RJ, Hendley KL, Aalbers BM, Furr-Stimming E, Hood AJ, Suescun J, Beurlot MR, Hendley RT, Schiess MC (2013) Altered nigrostriatal and nigrocortical functional connectivity in rapid eye movement sleep behavior disorder. Sleep 36, 1885-1892.

[73] Marder K, Wang Y, Alcalay RN, Mejia-Santana H, Tang M, Lee A, Raymond D, Mirelman A, Saunders-Pullman R, Clark L, Ozelius L, Orr-Urtreger A, Giladi N, Bressman S (2015) Age-specific penetrance of LRRK2 G2019S in the Michael J. Fox Ashkenazi Jewish LRRK2 Consortium. Neurology 85, 89-95.

[74] Hornykiewicz O (1998) Biochemical aspects of Parkinson's disease. Neurology 51, S2-S9.

[75] Braak H, Ghebremedhin E, Rub U, Bratzke H, Del Tredici K (2004) Stages in the development of Parkinson's disease-related pathology. Cell Tissue Res 318, 121-134.

[76] Langston JW (2006) The Parkinson's complex: Parkinsonism is just the tip of the iceberg. Ann Neurol 59, 591-596.

[77] Haehner A, Boesveldt S, Berendse HW, Mackay-Sim A, Fleischmann J, Silburn PA, Johnston AN, Mellick GD, Herting B, Reichmann H, Hummel T (2009) Prevalence of smell loss in Parkinson's disease-a multicenter study. Parkinsonism Relat Disord 15, 490-494. 
[78] Bohnen NI, Müller ML, Kotagal V, Koeppe RA, Kilbourn MA, Albin RL, Frey KA (2010) Olfactory dysfunction, central cholinergic integrity and cognitive impairment in Parkinson's disease. Brain 133, 1747-1754.

[79] Chahine LM, Weintraub D, Hawkins KA, Siderowf A, Eberly S, Oakes D, Seibyl J, Stern MB, Marek K, Jennings D; PARS Investigators (2016) Cognition in individuals at risk for Parkinson's: Parkinson associated risk syndrome (PARS) study findings. Mov Disord 31, 86-94.

[80] Su M, Wang S, Fang W, Zhu Y, Li R, Sheng K, Zou D, Han Y, Wang X, Cheng O (2015) Alterations in the limbic/paralimbic cortices of Parkinson's disease patients with hyposmia under resting-state functional MRI by regional homogeneity and functional connectivity analysis. Parkinsonism Relat Disord 21, 698-703.

[81] Yoneyama N, Watanabe H, Kawabata K, Bagarinao E, Hara K, Tsuboi T, Tanaka Y, Ohdake R, Imai K, Masuda M, Hattori T, Ito M, Atsuta N, Nakamura T, Hirayama M, Maesawa S, Katsuno M, Sobue G (2018) Severe hyposmia and aberrant functional connectivity in cognitively normal Parkinson's disease. PLoS One 13, 0190072.

[82] Aarsland D, Pahlhagen S, Ballard CG, Ehrt U, Svenningsson P (2012) Depression in Parkinson diseaseepidemiology, mechanisms and management. Nat Rev Neurol 8, 35-47.

[83] Lou Y, Huang P, Li D, Cen Z, Wang B, Gao J, Xuan M, Yu H, Zhang M, Luo W (2015) Altered brain network centrality in depressed Parkinson's disease patients. Mov Disord 30, 1777-1784.

[84] Wen X, Wu X, Liu J, Li K, Yao L (2013) Abnormal baseline brain activity in non-depressed Parkinson's disease and depressed Parkinson's disease: A resting-state functional magnetic resonance imaging study. PLoS One $\mathbf{8}$, 63691.

[85] Koenigs M, Grafman J (2009) The functional neuroanatomy of depression: Distinct roles for ventromedial and dorsolateral prefrontal cortex. Behav Brain Res 201, 239-243.

[86] Miller EK, Cohen JD (2001) An integrative theory of prefrontal cortex function. Annu Rev Neurosci 24, 167-202.

[87] Sheng K, Fang W, Su M, Li R, Zou D, Han Y, Wang X, Cheng O (2014) Altered spontaneous brain activity in patients with Parkinson's disease accompanied by depressive symptoms, as revealed by regional homogeneity and functional connectivity in the prefrontal-limbic system. PLoS One 9, 84705.

[88] Hu X, Song X, Yuan Y, Li E, Liu J, Liu W, Liu Y (2015) Abnormal functional connectivity of the amygdala is associated with depression in Parkinson's disease. Mov Disord 30, 238-244.

[89] Baggio HC, Segura B, Garrido-Millan JL, Marti MJ, Compta Y, Valldeoriola F, Tolosa E, Junque C (2015) Resting-state frontostriatal functional connectivity in Parkinson's disease-related apathy. Mov Disord 30, 671679.

[90] Skidmore FM, Yang M, Baxter L, von Deneen K, Collingwood J, He G, Tandon R, Korenkevych D, Savenkov A, Heilman KM, Gold M, Liu Y (2013) Apathy, depression, and motor symptoms have distinct and separable resting activity patterns in idiopathic Parkinson disease. Neuroimage 81, 484-495.

[91] Friedman JH, Friedman H (2001) Fatigue in Parkinson's disease: A nine-year follow-up. Mov Disord 16, 11201122 .
[92] Tessitore A, Giordano A, De Micco R, Caiazzo G, Russo A, Cirillo M, Esposito F, Tedeschi G (2016) Functional connectivity underpinnings of fatigue in "Drug-Naïe" patients with Parkinson's disease. Mov Disord 31, 1497 1505 .

[93] Agosta F, Pievani M, Geroldi C, Copetti M, Frisoni GB, Filippi M (2012) Resting state fMRI in Alzheimer's disease: Beyond the default mode network. Neurobiol Aging 33, 1564-1578.

[94] Rocca MA, Valsasina P, Absinta M, Riccitelli G, Rodegher ME, Misci P, Rossi P, Falini A, Comi G, Filippi M (2010) Default-mode network dysfunction and cognitive impairment in progressive MS. Neurology 74, 12521259.

[95] Tedeschi G, Trojsi F, Tessitore A, Corbo D, Sagnelli A, Paccone A, D'Ambrosio A, Piccirillo G, Cirillo M, Cirillo S, Monsurró MR, Esposito F (2012) Interaction between aging and neurodegeneration in amyotrophic lateral sclerosis. Neurobiol Aging 33, 886-898.

[96] Wolters AF, van de Weijer SCF, Leentjens AFG, Duits AA, Jacobs HIL, Kuijf ML (2019) Resting-state fMRI in Parkinson's disease patients with cognitive impairment: A meta-analysis. Parkinsonism Relat Disord 62, 16-27.

[97] Tessitore A, Esposito F, Vitale C, Santangelo G, Amboni M, Russo A, Corbo D, Cirillo G, Barone P, Tedeschi G (2012) Default-mode network connectivity in cognitively unimpaired patients with Parkinson disease. Neurology 79, 2226-2232.

[98] Olde Dubbelink KT, Schoonheim MM, Deijen JB, Twisk JW, Barkhof F, Berendse HW (2014) Functional connectivity and cognitive decline over 3 years in Parkinson disease. Neurology 83, 2046-2053.

[99] Amboni M, Tessitore A, Esposito F, Santangelo G, Picillo M, Vitale C, Giordano A, Erro R, de Micco R, Corbo D, Tedeschi G, Barone P (2015) Resting-state functional connectivity associated with mild cognitive impairment in Parkinson's disease. J Neurol 262, 425-434.

[100] Díez-Cirarda M, Strafella AP, Kim J, Peña J, Ojeda N, Cabrera-Zubizarreta A, Ibarretxe-Bilbao N (2018) Dynamic functional connectivity in Parkinson's disease patients with mild cognitive impairment and normal cognition. Neuroimage Clin 17, 847-855.

[101] Zhan ZW, Lin LZ, Yu EH, Xin JW, Lin L, Lin HL, Ye QY, Chen XC, Pan XD (2018) Abnormal resting-state functional connectivity in posterior cingulate cortex of Parkinson's disease with mild cognitive impairment and dementia. CNS Neurosci Ther 24, 897-905.

[102] Rektorova I, Krajcovicova L, Marecek R, Mik1 M (2012) Default mode network and extrastriate visual resting state network in patients with Parkinson's disease dementia. Neurodegener Dis 10, 232-237.

[103] Chen B, Fan GG, Liu H, Wang S (2015) Changes in anatomical and functional connectivity of Parkinson's disease patients according to cognitive status. Eur J Radiol 84, 1318-1324.

[104] Baggio HC, Segura B, Sala-Llonch R, Marti MJ, Valldeoriola F, Compta Y, Tolosa E, Junqué C (2015) Cognitive impairment and resting-state network connectivity in Parkinson's disease. Hum Brain Mapp 36, 199212.

[105] Williams-Gray CH, Foltynie T, Brayne CE, Robbins TW, Barker RA (2007) Evolution of cognitive dysfunction in an incident Parkinson's disease cohort. Brain 130, 17871798. 
[106] Cerasa A, Koch G, Donzuso G, Mangone G, Morelli M, Brusa L, Stampanoni Bassi M, Ponzo V, Picazio S, Passamonti L, Salsone M, Augimeri A, Caltagirone C, Quattrone A (2015) A network centred on the inferior frontal cortex is critically involved in levodopa-induced dyskinesias. Brain 138, 414-427.

[107] Herz DM, Haagensen BN, Nielsen SH, Madsen KH, Løkkegaard A, Siebner HR (2016) Resting-state connectivity predicts levodopa-induced dyskinesias in Parkinson's disease. Mov Disord 31, 521-529.
[108] Cerasa A, Morelli M, Augimeri A, Salsone M, Novellino F, Gioia MC, Arabia G, Quattrone A (2013) Prefrontal thickening in PD with levodopa-induced dyskinesias: New evidence from cortical thickness measurement. Parkinsonism Relat Disord 19, 123-125. 